\title{
Long-Term Simulation of Daily Streamflow Using Radar Rainfall and the SWAT Model: A Case Study of the Gamcheon Basin of the Nakdong River, Korea
}

\author{
Huiseong Noh, ${ }^{1}$ Jongso Lee, ${ }^{2}$ Narae Kang, ${ }^{2}$ Dongryul Lee, \\ Hung Soo Kim, ${ }^{2}$ and Soojun Kim ${ }^{3}$ \\ ${ }^{1}$ Water Resources Research Division, Korea Institute of Civil Engineering and Building Technology (KICT), \\ Goyang 10223, Republic of Korea \\ ${ }^{2}$ Department of Civil Engineering, Inha University, Incheon 22212, Republic of Korea \\ ${ }^{3}$ Columbia Water Center, Earth Institute, Columbia University, New York, NY 10027, USA \\ Correspondence should be addressed to Soojun Kim; soojun78@gmail.com
}

Received 23 February 2016; Revised 17 June 2016; Accepted 19 July 2016

Academic Editor: Gwo-Fong Lin

Copyright (C) 2016 Huiseong Noh et al. This is an open access article distributed under the Creative Commons Attribution License, which permits unrestricted use, distribution, and reproduction in any medium, provided the original work is properly cited.

\begin{abstract}
In recent years, with the increasing need for improving the accuracy of hydrometeorological data, interests in rain-radar are also increasing. Accordingly, with high spatiotemporal resolution of rain-radar rainfall data and increasing accumulated data, the application scope of rain-radar rainfall data into hydrological fields is expanding. To evaluate the hydrological applicability of rainradar rainfall data depending on the characteristics of hydrological model, this study applied $R_{\text {gauge }}$ and $R_{\text {radar }}$ to a SWAT model in the Gamcheon stream basin of the Nakdong River and analyzed the effect of rainfall data on daily streamflow simulation. The daily rainfall data for $R_{\text {gauge }}, R_{Z}$, and $R_{K_{\mathrm{DP}}}$ were utilized as input data for the SWAT model. As a result of the daily runoff simulation for analysis periods using $R_{Z(\mathrm{P})}$ and $R_{K_{\mathrm{DP}}(\mathrm{P})}$, the simulation which utilized $R_{\text {gauge }}$ reflected the rainfall-runoff characteristics better than the simulations which applied $R_{Z(\mathrm{P})}$ or $R_{K_{\mathrm{DP}}(\mathrm{P})}$. However, in the rainy or wet season, the simulations which utilized $R_{Z(\mathrm{P})}$ or $R_{K_{\mathrm{DP}}(\mathrm{P})}$ were similar to or better than the simulation that applied $R_{\text {gauge }}$. This study reveals that analysis results and degree of accuracy depend significantly on rainfall characteristics (rainy season and dry season) and QPE algorithms when conducting a runoff simulation with radar.
\end{abstract}

\section{Introduction}

With the influence of climate change and climate variability, the magnitude and frequency of extreme hydrological events increase, which makes the world suffer from natural disasters such as floods, droughts, landslides, avalanches, and so forth. Particularly in Korea, people are suffering from localized heavy rainfall and flash flood in some years and from severe drought in other years. Therefore, a study on a more accurate and comprehensive analysis and prediction is required in order to adapt to climate change and climate variability and reduce human life and property damages from floods or droughts caused by extreme hydrological events. To this end, the necessity of high-resolution hydrometeorological data with high accuracy is emphasized. In particular, rainfall is used as basic data for all interpretations related to hydrologic cycle and the water resources plan and management and also has a nonlinear relationship with other hydrological factors and environmental ones (i.e., runoff, soil moisture, erosion, water quality, etc.) [1]. For this reason, acquiring exact rainfall data is very important.

In a runoff simulation for the analysis of floods and droughts, rainfall is used as input data for rainfall-runoff model and many studies have been conducted for measuring exact rainfall in terms of time and space. Particularly for improving the accuracy of the spatiotemporal rainfall, hydrological and meteorological fields have recently paid more interest in estimating the precipitation data with a new 
Remote Sensing Technology including rain or weather radar (in the following, we will frequently omit the term "rain" or "weather") and artificial satellite.

In particular, radar data has advantages in that it can continue to provide rainfall information with high spatial and temporal resolutions. In early times of rainfall observation using radar, the rainfall intensity can be determined from the horizontal reflectivity $\left(Z_{\mathrm{H}}\right)$ observed using singlepolarization radar. However, there is difficulty in measuring rainfall because its changing characteristics can vary depending on the type of clouds or developmental conditions, temporal and spatial location, and type of hydrometer. It has since become possible to measure various dual-polarization variables $\left(Z_{\mathrm{H}}, Z_{\mathrm{V}}, Z_{\mathrm{DR}}, K_{\mathrm{DP}}, \rho_{\mathrm{HV}}\right.$, etc.) using dual-polarization radar. In this process, precipitation estimation techniques can be developed.

Due to the advantages of radar, many studies in hydrological and meteorological fields that utilize radar data are being actively carried out. Utilization of radar data can be largely divided into two aspects. The first is general radar image data which analyzes the current status of rainfall and the second is grid-type rainfall distribution data for calculating flood flow [2]. In hydrological fields, two major research areas include hydrologic phenomena in various basins (including natural basins and urban basins) [2-15] and the spatial and temporal variability of rainfall $[16,17]$. To evaluate previous studies which applied radar rainfall data to the Soil \& Water Assessment Tool (SWAT) rainfall-runoff model used in this study, Di Luzio and Arnold [18] applied NEXRAD Stage III data to the SWAT model as part of the Distributed Model Intercomparison Project (DMIP) to carry out the first simulation of daily runoff and Jayakrishnan et al. [19] used WSR-88D data obtained from the Sondu River in Kenya to carry out a simulation of runoff and water quality. Recently, Jeong et al. [20] used CAPPI data of single-polarization radar to measure the optimal grid size for radar reflectivity and used the SWAT model and as a result of the runoff simulation proposed the optimal grid size of radar rainfall data in the applicable basin to be $4-8 \mathrm{~km}$. Furthermore, Sexton et al. [21] and Price et al. [22] used the SWAT model to compare the runoff discharge from NEXRAD data with that from rain gauge data and suggested that radar rainfall data could be utilized in a useful way in basins where rain gauge data is insufficient.

As shown above, previous studies have presented various evaluation results of the hydrological applicability of radar rainfall data depending on the radar data used, target area, and hydrological model applied. However, most of the studies have largely focused on short duration rainfall events or longterm runoff simulation for about a month or a season using radar data. In other words, there are few studies on the hydrological applicability in terms of long-term runoff for water resource management. However, the accumulated rain radar rainfall data are considered to be used sufficiently for a long-term hydrologic analysis.

Therefore, this study aims to review the hydrological applicability of radar rainfall data in a long-term runoff analysis for more than one year with the characteristics of single- and dual-polarization radar rainfall data.
To this end, the procedure employed in this study consists of the following steps:

(1) Collect hydrometeorological input data on hydrological systems in the basin.

(2) Create single-polarization rain radar-derived rainfall $\left(R_{Z(\mathrm{P})}\right)$ and dual-polarization rain radar-derived rainfall $\left(R_{K_{\mathrm{DP}}(\mathrm{P})}\right)$ and compare/analyze rain gauge data $\left(R_{\text {gauge }}\right)$.

(3) Build the SWAT model and conduct calibration and validation as well as runoff simulation over the analysis period utilizing $R_{\text {gauge }}, R_{Z(\mathrm{P})}$, and $R_{K_{\mathrm{DP}}(\mathrm{P})}$ as input data.

(4) Analyze the characteristics and applicability of $R_{\text {gauge }}$, $R_{Z(\mathrm{P})}$, and $R_{K_{\mathrm{DP}}(\mathrm{P})}$ in long-term runoff analysis.

\section{Study Area and Rainfall Data}

2.1. Study Area. In this study, the Gamcheon stream basin of the Nakdong River in Korea (see Figure 1) was selected as the area of study to evaluate the hydrologic applicability of radar rainfall data. The Gamcheon stream is the first tributary of the Nakdong River and its stream length is $69 \mathrm{~km}$. The area of the Gamcheon stream basin is about $1,005.3 \mathrm{~km}^{2}$ and it occupies about $4.3 \%$ of the Nakdong River basin. The basin is a dendritic form basin. Relatively wider alluvial plains are developed midsteam and downstream in the form of a basin surrounded by hilly mountains. The average channel width is about $230-350 \mathrm{~m}$ and the bed slope is about $0.0021-0.0014$. Toward the upper stream, the bed slope tends to increase. The average annual rainfall is about $1,100 \mathrm{~mm}$. The Gamcheon stream basin has no influx of streamflows from other basins and there are few impacts due to artificial variations of the streamflow.

2.2. Rain Gauge Data $\left(R_{\text {gauge }}\right)$ and Radar Rainfall Data $\left(R_{Z(P)}, R_{K_{D P}(P)}\right)$. To compare the applied hydrological simulations which utilized $R_{\text {radar }}$, rainfall data at 5 rain gauge stations within the basin were collected from the Water Management Information System (WAMIS) operated by the Ministry of Land, Infrastructure, and Transport (MOLIT) from 2010 to 2012 (Figure 1). In Korea, MOLIT, Korea Meteorological Administration (KMA), Korea Water Resources Corporation (K-water), and Korea Rural Community Corporation (KRC) carry out hydrologic observations for their own purposes, but the hydrological observation is largely supervised by MOLIT, which is responsible for flood forecasting and warning as well as water management.

In this study, the radar data used was the Mt. Bisl rain radar data from MOLIT (Figure 1). MOLIT constructs a radar rainfall estimation system by carrying out a series of processes including quality control of radar data and application of Quantitative Precipitation Estimation (QPE) algorithms and provides rain radar-derived rainfall data.

The major procedures includes (1) import of observed radar data, (2) data quality control (removal of nonmeteorologic echoes), (3) creation of radar rainfall field (3 types of spatial fields: LEMAP (Lowest Elevation MAP), PPI (Plan Position Indicator), and CAPPI (Constant Altitude Plan 


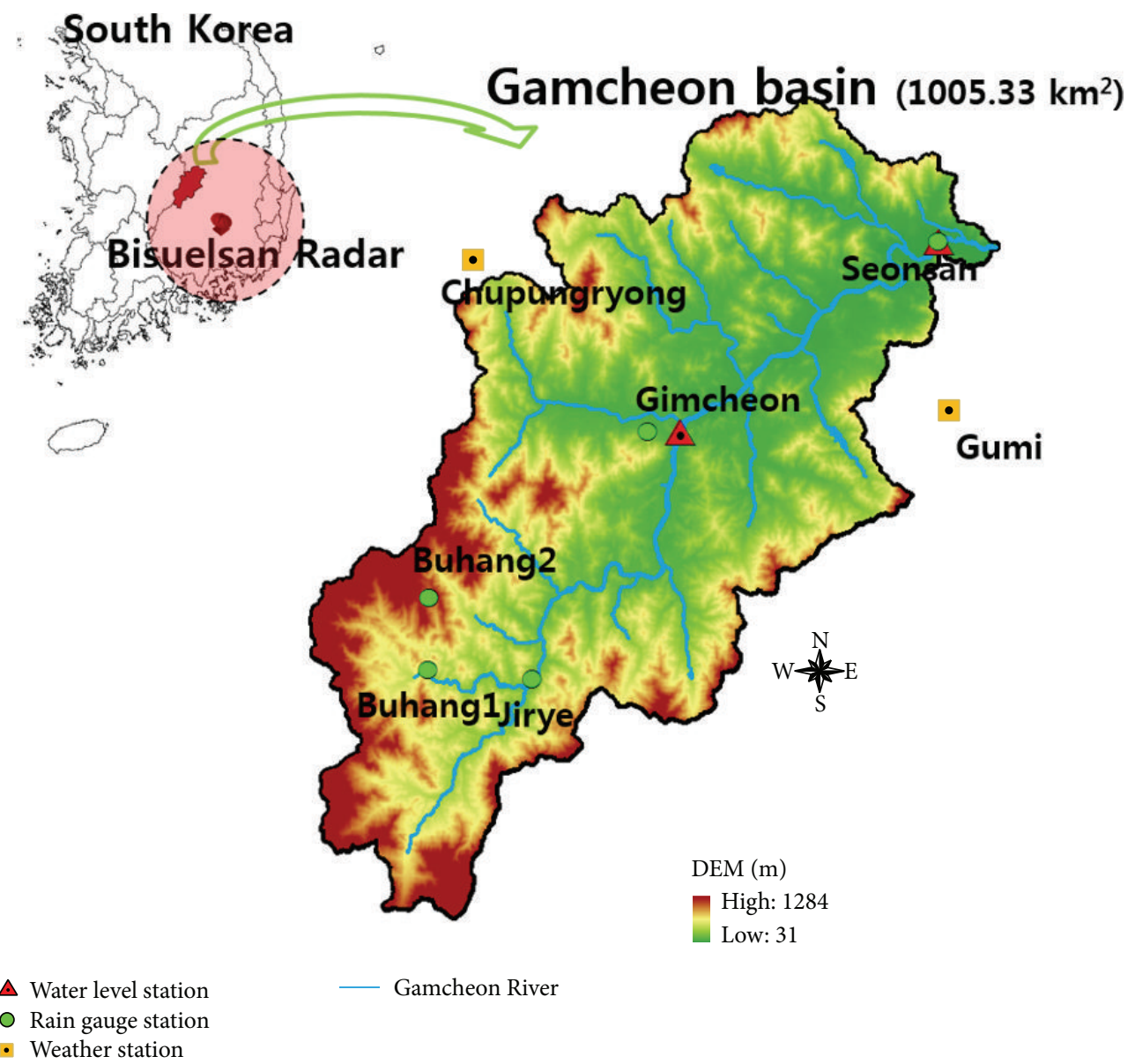

Figure 1: Study basin.

Position Indicator)), (4) radar rainfall estimation (3 types of algorithms: $R_{Z}, R_{Z \mathrm{DR}}$, and $\left.R_{K_{\mathrm{DP}}}\right)$, (5) radar rainfall adjustment using ground rainfall, (6) calculation of point rainfall and areal rainfall of subwatershed using adjusted radar rainfall, and (7) storage of rainfall data in a DB system. In particular, LEMAP (Lowest Elevation MAP) shows a radar Rrinfall field based on the radar reflectivity data observed at a very close altitude from the ground. Figure 2 represents the procedure of the radar rainfall estimation system currently employed by MOLIT.

In this study, we applied the following rainfall estimation algorithms to compare the hydrological applicability of $R_{\text {radar }}$. First, $R_{Z}$ and $R_{K_{\mathrm{DP}}}$ are calculated using (1) and (2). Equation (1) has the same shape as the existing single-polarization with the so-called $Z-R$ relationship $\left(Z=a R^{b}\right)$ :

$$
R_{Z}=1.70 \times 10^{-2} \times Z^{0.714}
$$

The inverse of this equation is $Z=300 R^{1.4}$. Herein, $Z$ is the reflectance of radar in the horizontal direction observed with single-polarization radar, $Z_{\mathrm{H}}$. Equation (1) is an empirical equation appropriate for rainfall types between straight form rainfall and convective rainfall, which are at intermediate level or higher in terms of rainfall intensity according to the characteristics of rainfall in the summer [23].
Next, (2) and (3) were proposed by Ryzhkov et al. [24] as a prototype for dual-polarization radar of WSR$88 \mathrm{D}$ in the United States. Generally, the radar reflectivity $(Z)$, differential reflectivity $\left(Z_{\mathrm{DR}}\right)$, and specific differential phase shift $\left(K_{\mathrm{DP}}\right)$ are used in dual-polarization radar rainfall estimation. Also, the drop size distribution (DSD) depends on the rain intensity. Therefore, to adjust for any errors in the process of obtaining $R_{K_{\mathrm{Dp}}}$, each formula used depends on the rain intensity calculated by $R_{Z}$, as shown in (3) [24]. One has

$$
\begin{aligned}
R_{K_{\mathrm{DP}}} & =44.0\left|K_{\mathrm{DP}}\right|^{0.822} \times \operatorname{sign}\left(K_{\mathrm{DP}}\right), \\
R & =\frac{\overline{R_{Z}}}{f_{1}\left(\overline{Z_{\mathrm{DR}}}\right)} \quad \text { if } \overline{R_{Z}}<6 \mathrm{~mm} / \mathrm{h}, \\
R & =\frac{\overline{R_{K_{\mathrm{DP}}}}}{f_{2}\left(\overline{Z_{\mathrm{DR}}}\right)} \quad \text { if } 6<\overline{R_{Z}}<50 \mathrm{~mm} / \mathrm{h}, \\
R & =\overline{R_{K_{\mathrm{DP}}}} \text { if } \overline{R_{Z}}>50 \mathrm{~mm} / \mathrm{h}, \\
f_{1}\left(\overline{Z_{\mathrm{DR}}}\right) & =0.4+5.0\left|Z_{\mathrm{dr}}-1\right|^{1.3}, \\
f_{2}\left(\overline{Z_{\mathrm{DR}}}\right) & =0.4+3.5\left|Z_{\mathrm{dr}}-1\right|^{1.7}, \\
\overline{Z_{\mathrm{dr}}} & =10^{0.1 \overline{Z_{\mathrm{DR}}(\mathrm{dB})}}
\end{aligned}
$$




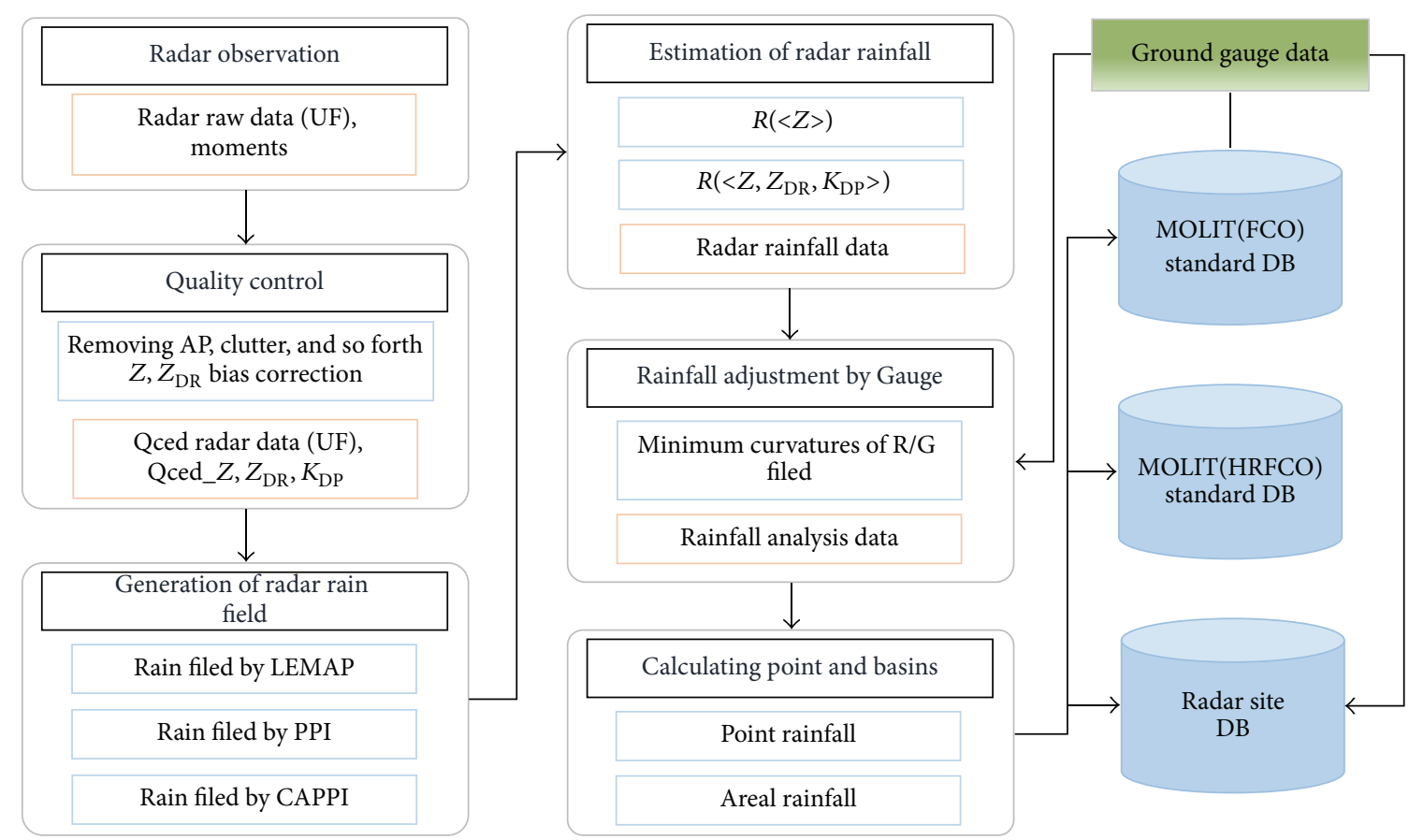

FIGURE 2: Radar data quality control and rainfall estimation procedures employed by MOLIT.

Here, $f_{1}$ and $f_{2}$, the functions of $R_{Z}$ and $R_{K_{\mathrm{DP}}}$, are determined by utilizing (1), (2), and (4) and the reflectivity, $f_{1}\left(\overline{Z_{\mathrm{DR}}}\right)$ and $f_{2}\left(\overline{Z_{\mathrm{DR}}}\right)$, where $\overline{Z_{\mathrm{dr}}}$ is an adjustment factor depending on the shape of the drop size.

In this study, single-polarization rain radar-derived rainfall which considers the reflectivity $(Z)$ and can be described by (1) alone and dual-polarization rain radar-derived rainfall which involves all of the dual-polarization variables shown in (1) to (4) expressed as $R_{K_{\mathrm{DP}}}, R_{Z}$, and $R_{K_{\mathrm{DP}}}$ were utilized. The rainfall intensity $(\mathrm{mm} / \mathrm{hr})$ had an observational radius of $150 \mathrm{~km}$, a temporal resolution of $2.5 \mathrm{~min}$, and a spatial resolution of $125 \mathrm{~m} \times 125 \mathrm{~m}$ while applying the rainfall estimation algorithms shown above. To utilize as input data in the SWAT model, $R_{Z}$ and $R_{K_{\mathrm{DP}}}$ data were converted to daily rainfall by multiplying the rate of the observational cycle $(2.5 \mathrm{~min})$ and time. In this case, radar-derived point rainfall data $\left(R_{Z(\mathrm{P})}, R_{K_{\mathrm{DP}}(\mathrm{P})}\right)$ that belongs to the subbasin were recreated (Figure 4 ).

\section{SWAT Model}

3.1. SWAT Model and Input Data Buildup. The SWAT (Soil and Water Assessment Tool) model is a unit model of a basin developed by the USDA Agricultural Research Service (ARS) $[26,27]$. In particular, the SWAT model has advantages in that it can allow a hydrologic analysis of ungauged basins by conducting a predictive simulation of long-term rainfallrunoff and sediment movement within the basin. It also has the ability to quantify relative effects of water quality depending on forms of cultivation and climate/vegetation changes. To make a temporal/spatial analysis of hydrology and water quality using the SWAT model, it is necessary to obtain meteorological data that changes over time (daily amount of precipitation, temperature, wind speed, amount of sunshine, and relative humidity), the current status of land use spatially, soil attributes, and the Digital Elevation Model (DEM). The SWAT model is widely used because it is easy to generate major input values and it is possible to analyze the runoff of rainfall in basins, the occurrence of nonpoint pollution, and temporal/spatial changes.

In this study, the DEM was set at $30 \mathrm{~m} \times 30 \mathrm{~m}$ so that runoff of rainfall in the basins and actual stream within the basins can be well reproduced. As a land use map, the $1: 25,000$ classification land use map provided by WAMIS was used. As a soil map, the 1:50,000 reconnaissance soil map provided by WAMIS was used. Meteorological data including the mean daily wind speed $(\mathrm{m} / \mathrm{sec})$, daily average relative humidity (\%), daily maximum/minimum temperature $\left({ }^{\circ} \mathrm{C}\right)$, and daily quantity of horizontal solar radiation $\left(\mathrm{MJ} / \mathrm{m}^{2}\right)$ were obtained from western meteorological observing stations. Table 1 summarizes the input and output data of the SWAT model.

3.2. Model Parameter Calibration and Validation. To correct the parameters, we applied a trial-and-error method and calibration tool to increase the predictive accuracy of runoff discharge in the SWAT model. If the calibration procedure is properly planned, daily data collected over the course of one year is sufficient for the model calibration to obtain conceptually realistic estimates. In addition, the use of older data does not greatly influence the adjustment of parameters [28]. The periods of correction and calibration were 2010 and 2011, respectively, and the ground rainfall data and daily discharge data within basins used for the periods of 
correction, calibration, and simulation were provided by WAMIS and the Korea Hydrological Survey Center (KHSC).

As CANMX, CN2, ESCO, GW_REVAP, SOL_AWC, SOL_K, REVAPMN, and GWQMN among the parameters related to runoff discharge in the SWAT model react sensitively, CN2 was adjusted to correct observational values of the runoff discharge. In addition, to correct the base runoff, the parameters related to underground water (GW_REVAP, REVAPMN, and GWQMN) were calibrated. In other words, if the base runoff is simulated to be higher, GW_REVAP and GWQMN are increased and REVAPMN is reduced. If base runoff is simulated to be lower, the coefficients are calibrated reversely. The range of parameters and the shape of the input data are summarized in Table 2.

3.3. Model Applicability Evaluation Index. In this study, to evaluate the applicability of the SWAT model for the calibration, validation, and simulation periods, the Nash-Sutcliffe efficiency (NSE), percent bias (PBIAS (\%)), and RMSEobservations standard deviation ratio (RSR) were used. To determine the optimal value of each index, NSE $=1$, PBIAS $=$ 0 , and RSR $=0$, as shown in (3)-(5). The NSE is a normalized statistic that determines the relative magnitude of the residual variance ("noise") compared to the measured data variance ("information") [29]. PBIAS measures the average tendency of the simulated data to be larger or smaller than their observed counterparts [30]. RSR was calculated as the ratio of the RMSE and standard deviation of measured data [25]:

$$
\begin{aligned}
\text { NES } & =1-\left[\frac{\sum_{i=1}^{n}\left(Q_{i}^{\text {obs }}-Q_{i}^{\text {sim }}\right)^{2}}{\sum_{i=1}^{n}\left(Q_{i}^{\text {obs }}-Q^{\text {mean }}\right)^{2}}\right], \\
\text { PBIAS } & =\left[\frac{\sum_{i=1}^{n}\left(Q_{i}^{\text {obs }}-Q_{i}^{\text {sim }}\right)^{2} * 100}{\sum_{i=1}^{n}\left(Q_{i}^{\text {obs }}\right)}\right], \\
\text { RSR } & =\frac{\text { RMSE }_{\text {STDEV }}}{\text { obs }}=\frac{\left[\sqrt{\sum_{i=1}^{n}\left(Q_{i}^{\text {obs }}-Q_{i}^{\text {sim }}\right)^{2}}\right]}{\left[\sqrt{\sum_{i=1}^{n}\left(Q_{i}^{\text {obs }}-Q_{i}^{\text {mean }}\right)^{2}}\right]} .
\end{aligned}
$$

Herein, $Q_{i}^{\text {obs }}$ is the $i$ th observed streamflow, $Q_{i}^{\text {sim }}$ is the $i$ th simulated streamflow, $Q^{\text {mean }}$ is the mean of the observed streamflow, and $n$ is the total number of observations.

Ramanarayanan et al. [31] suggested that if $R^{2}$ is 0.5 or higher and NES is 0.4 or higher, the model simulates natural phenomenon well. Moriasi et al. [25] claimed that, based on examples of existing various models and research data, index values of the model simulation of NSE $>0.50$, RSR $<0.70$, and PBIAS $\pm 25 \%$ are satisfactory. In particular, Moriasi et al. [25] proposed the criteria for setting the general performance rating in the model of runoff discharge, as shown in Table 3. This criteria is based on monthly unit runoff discharge, but the model simulation is poorer with a shorter time step than a longer time step (e.g., daily versus monthly or yearly) [32]. Therefore, these criteria can be used to evaluate the results of calibration, validation, and simulation obtained in this study.
TABLE 1: Input and output data of the SWAT model.

\begin{tabular}{lc}
\hline & SWAT input data \\
\hline Pemporal analysis & Precipitation \\
Temperature & Wind speed \\
Solar radiation & Relative humidity \\
\hline Spatial analysis & Land use \\
& Soil \\
& Topography \\
\hline & SWAT output data \\
\hline Daily/monthly/yearly & Runoff/soil erosion/water quality for \\
& subwatershed \\
& Runoff/soil erosion/water quality for each \\
& segment
\end{tabular}

3.4. Application of Radar Rainfall Data in the SWAT Model. A rainfall station should be installed to represent the local distribution of rainfall in a basin. In this case, five rainfall stations (Seonsan, Gimcheon, Jirye, Buhang 1, and Buhang 2) are located in the Gamcheon stream basin of the Nakdong River and the density of rainfall station is about $201.1 \mathrm{~km}^{2} /$ station (basin area is $1,005.3 \mathrm{~km}^{2}$ ). This density of the rainfall station is above the minimum criteria recommended by World Metrological Organization (WMO) (mountains and hills: $250-575 \mathrm{~km}^{2} /$ station), but it is not sufficient for the criteria for flood forecasting and warning (generally, $50 \mathrm{~km}^{2} /$ station) recommended by the Design Criteria Rivers Commentary of Korea Water Resources Association (KWRA) [33]. This study aimed to propose the method(s) to compensate the problems occurring during hydrologic analysis by using a semidistributed model, which might appear due to intermittence of rain gauge. In other words, it is to generate rain radar data at the applicable site by using rain radar rainfall data if rain radar rainfall data at the site without rain gauge data are required.

Radar-derived rainfall data can be used in a useful way in basins where ground observation data (rainfall station) is not sufficiently guaranteed. Therefore, this study creates radarderived point rainfall data $\left(R_{Z(\mathrm{P})} ; R_{K_{\mathrm{DP}}(\mathrm{P})}\right)$ at central points of 42 subbasins divided when building the SWAT model to demonstrate the advantages of radar-derived rainfall data.

In other words, the SWAT model uses the closest rain gauge station (Buhang 1 station) to interpret \#7 subbasin (\#7 basin is at the utmost bottom of the figure), as shown in Figure 3(b). Therefore, it is difficult to simulate appropriate runoff discharge if there is difficulty in taking into account the temporal and spatial characteristics of rainfall because the size of basin is large or there are not many rain gauge stations in the basin.

\section{Results and Discussion}

In this study, we utilized 2012 as the year for simulation taking into account the observation period and accuracy of each 
TABLE 2: Range and input data of the SWAT model parameters.

\begin{tabular}{|c|c|c|c|}
\hline Variable name & Definition & Range & Input file \\
\hline GW_DELAY & Groundwater Delay time & $0-500$ & ${ }^{*}$.gw \\
\hline ALPHA_BF & Baseflow Alpha Factor & $0-1$ & ${ }^{*} \cdot g \mathrm{gw}$ \\
\hline GW_REVAP & Groundwater "revap" coefficient & $0.02-0.2$ & ${ }^{*} . \mathrm{gw}$ \\
\hline GWQMN & $\begin{array}{l}\text { Threshold depth of water in the shallow aquifer required for return } \\
\text { flow to occur }\end{array}$ & $0-5,000$ & ${ }^{*}$.gw \\
\hline REVAPMN & Threshold depth of water in the shallow aquifer for "revap" to occur & $0-500$ & *.gw \\
\hline ESCO & Soil evaporation compensation factor & $0.01-1.0$ & ${ }^{*}$.hru \\
\hline SLSOIL & Slope length for lateral subsurface flow & $0-10$ & ${ }^{*} \cdot$ hru \\
\hline LET_TIME & Lateral flow travel time & $0-10$ & ${ }^{*}$.hru \\
\hline LET_SED & Sediment concentration in lateral and groundwater flow & $0-10$ & ${ }^{*}$.hru \\
\hline $\mathrm{CH}_{-} \mathrm{K}(2)$ & Effective hydraulic conductivity in main channel alluvium & $-0.01-150$ & ${ }^{*}$.rte \\
\hline $\mathrm{CH} \_\mathrm{N}(2)$ & Manning's " $n$ " value for the main channel & $0-0.3$ & ${ }^{*}$.rte \\
\hline $\mathrm{CN} 2$ & SCS Curve Number & $30-98$ & ${ }^{*}$.mgt \\
\hline SOL_AWC & Available water capacity & $0-1$ & ${ }^{*}$.sol \\
\hline SOL_K & Saturated hydraulic conductivity & $0-2,000$ & ${ }^{*}$.sol \\
\hline MSK_CO2 & $\begin{array}{l}\text { Calibration coefficient used to control the impact of the storage time } \\
\text { constant for low flow }\end{array}$ & $0-10$ & ${ }^{*}$.bsn \\
\hline SURLAG & Surface runoff lag time & $1-24$ & ${ }^{*}$.bsn \\
\hline SFTMP & Snowfall temperature & $-5-5$ & ${ }^{*}$.bsn \\
\hline SMTMP & Snow melt base temperature & $-5-5$ & ${ }^{*}$.bsn \\
\hline SMFMX & Melt factor for snow on June 21 & $1.7-6.5$ & ${ }^{*}$.bsn \\
\hline SMFMN & Melt factor for snow on December 21 & $1.7-6.5$ & ${ }^{*}$.bsn \\
\hline
\end{tabular}

TABLE 3: General performance ratings for a monthly time step.

\begin{tabular}{lccr}
\hline Performance rating $^{\text {RSR }}$ & NSE & PBIAS (\%) \\
\hline Very good $^{\mathrm{a}}$ & $0.00 \leq \mathrm{RSR} \leq 0.50$ & $0.75<\mathrm{NSE} \leq 1.00$ & PBIAS $< \pm 10$ \\
Good $^{\mathrm{a}}$ & $0.50<\mathrm{RSR} \leq 0.60$ & $0.65<\mathrm{NSE} \leq 0.75$ & $\pm 10 \leq$ PBIAS $< \pm 15$ \\
Satisfactory $^{\mathrm{a}}$ & $0.60<\mathrm{RSR} \leq 0.70$ & $0.50<\mathrm{NSE} \leq 0.65$ & $\pm 15 \leq$ PBIAS $< \pm 25$ \\
Unsatisfactory $^{\mathrm{a}}$ & $\mathrm{RSR}>0.70$ & NSE $\leq 0.50$ & PBIAS $\geq \pm 25$ \\
\hline
\end{tabular}

${ }^{\mathrm{a}}[25]$.

data set, established the SWAT model in the basins prior to runoff simulation, and created $R_{Z(\mathrm{P})}$ and $R_{K_{\mathrm{DP}}(\mathrm{P})}$, as shown in Figure 3 . In addition, we made a simple comparative analysis of $R_{Z(\mathrm{P})}, R_{K_{\mathrm{DP}}(\mathrm{P})}$, and $R_{\text {gauge }}$.

4.1. Comparison of Rainfall Data. Figure 4 represents the results of the comparison of the basin average rainfall accumulated for the period of simulation (2012).

As a result of comparing the average basin rainfall accumulated during the period of simulation (2012), $R_{\text {gauge }}$ is $1,281.4 \mathrm{~mm}$ and $R_{Z(\mathrm{P})}$ and $R_{K_{\mathrm{DP}}(\mathrm{P})}$ are $1,272.6 \mathrm{~mm}$ and $1,450.6 \mathrm{~mm}$, respectively. Compared to the ground observation rainfall, $R_{Z(\mathrm{P})}$ is underestimated by about $0.7 \%(8.8 \mathrm{~mm})$ and $R_{K_{\mathrm{DP}}(\mathrm{P})}$ is overestimated about $13.2 \%(169.2 \mathrm{~mm})$. In the scatter plot which shows the accumulated rainfall and correlation of $R_{\text {gauge }}$ and $R_{Z(\mathrm{P})}$ or $R_{K_{\mathrm{DP}}(\mathrm{P})}$ (inside Figure 4 ), the correlation coefficients and root-mean-square deviation error values between $R_{Z(\mathrm{P})}$ or $R_{K_{\mathrm{DP}}(\mathrm{P})}$ and $R_{\text {gauge }}$ are 0.968 and 0.976 and 2.926 and 2.848 , respectively. This suggests that the values obtained for $R_{K_{\mathrm{DP}}(\mathrm{P})}$ are better. However, as a result of comparing the rainfall of the Nile depending on the period, $R_{Z(\mathrm{P})}$ and $R_{K_{\mathrm{DP}}(\mathrm{P})}$ represent the characteristics of rainfall in the rainy or wet season (heavy rainfall and in the summer when typhoons occur frequently: Jun. to Sept.) relatively well but are overestimated in the dry season (periods other than the rainy or wet season: spring, fall, and winter). In particular, in the dry season, the PBIAS results utilizing $R_{Z(\mathrm{P})}$ and $R_{K_{\mathrm{DP}}(\mathrm{P})}$ are in the range of about $11 \%$ to $37 \%$ (overestimated). Given that the annual PBIAS is about $0.7 \%$ to $13.2 \%, R_{Z(\mathrm{P})}$ and $R_{K_{\mathrm{DP}}(\mathrm{P})}$ are very low in terms of accuracy for rainfall estimation in dry seasons (Table 4). Tables 5 and 6 show data for the ten (10) days in which daily rainfall data of $R_{Z(\mathrm{P})}$ and $R_{K_{\mathrm{DP}}(\mathrm{P})}$ are overestimated and underestimated the most compared to $R_{\text {gauge }}$. As shown in the overestimation list, $R_{K_{\mathrm{DP}}(\mathrm{P})}$ has higher variations except for the abnormal observation at $R_{Z(\mathrm{P})}$ (Sept. 12, 2012) and in the underestimation list, $R_{Z(\mathrm{P})}$ has higher variations.

4.2. Simulated Streamflow Results. As mentioned earlier, the entire period of analysis (2010 to 2013) was divided into 


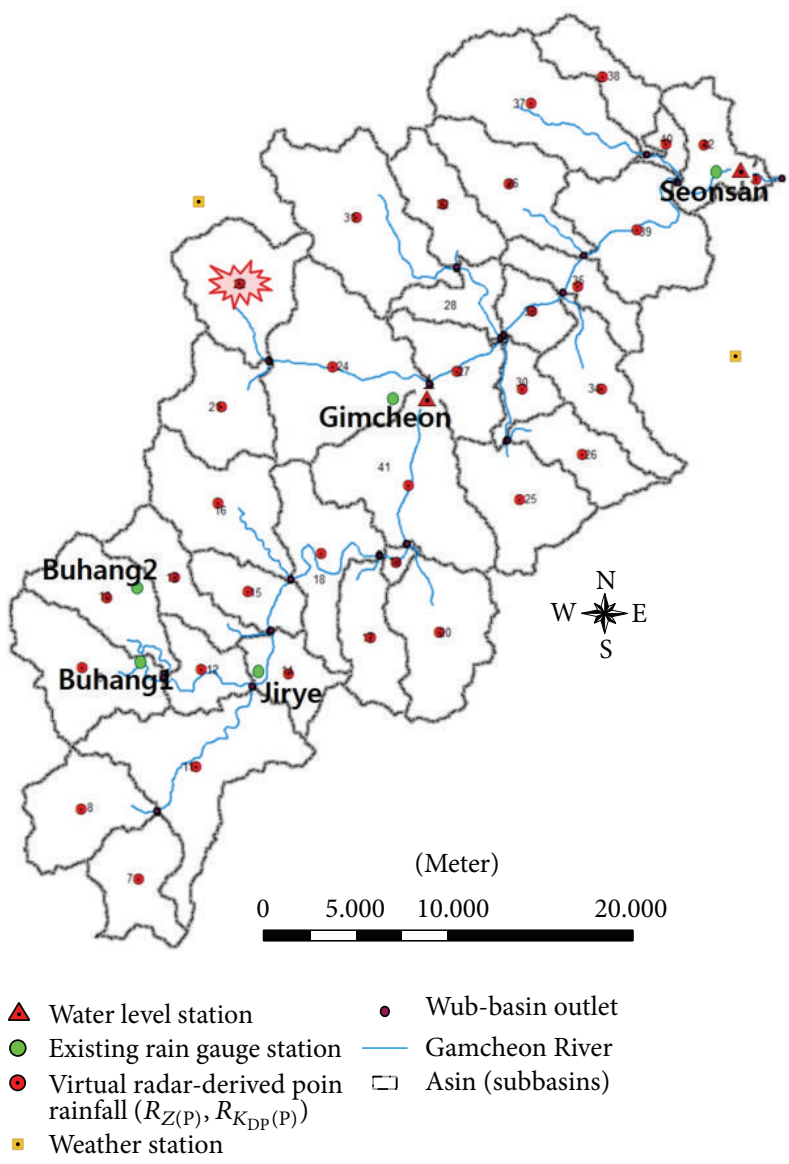

(a)

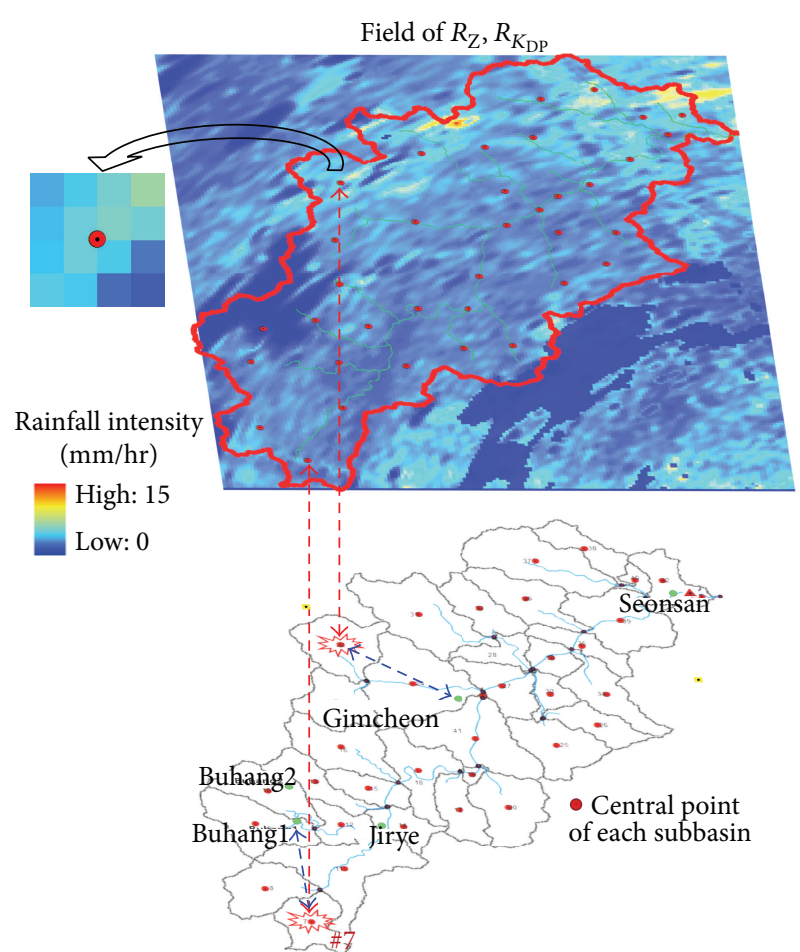

(b)

FIGURE 3: Creation of virtual radar-derived point rainfall $\left(R_{Z(\mathrm{P})}, R_{K_{\mathrm{DP}}(\mathrm{P})}\right)$.

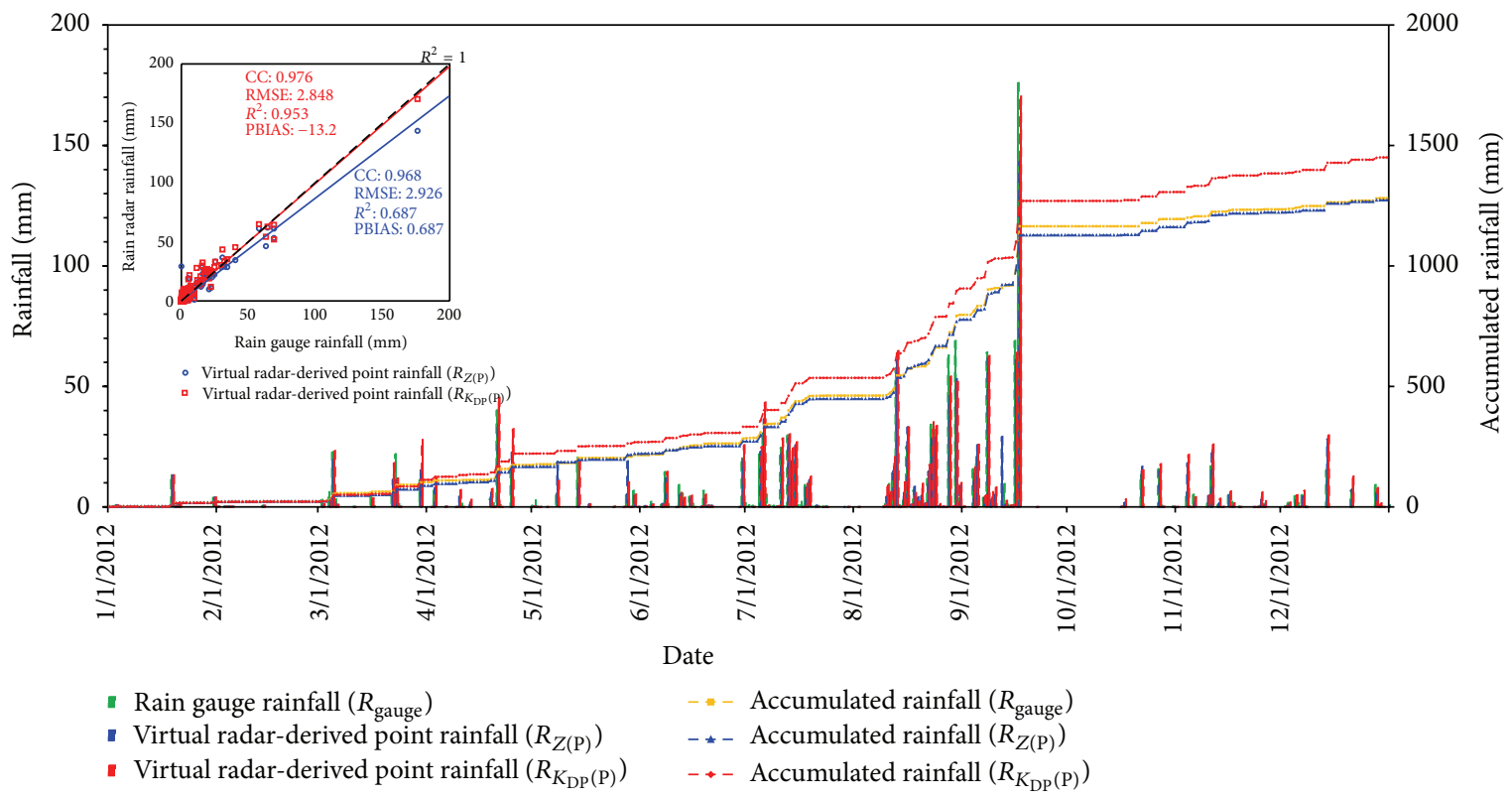

FIGURE 4: Comparison of basin average rainfalls for the different rainfall data types. 
TABLE 4: Summary of the statistics of basin average rainfall for the different rainfall data types.

\begin{tabular}{lccccccccccc}
\hline Classification & \multicolumn{3}{c}{ Accumulated rainfall $(\mathrm{mm})$} & \multicolumn{2}{c}{$\mathrm{CC}$} & \multicolumn{2}{c}{ RMSE } & \multicolumn{2}{c}{$R^{2}$} & \multicolumn{2}{c}{ PBIAS (\%) } \\
& $R_{\text {gauge }}$ & $R_{Z(\mathrm{P})}$ & $R_{K_{\mathrm{DP}}(\mathrm{P})}$ & $R_{Z(\mathrm{P})}$ & $R_{K_{\mathrm{DP}}(\mathrm{P})}$ & $R_{Z(\mathrm{P})}$ & $R_{K_{\mathrm{DP}}(\mathrm{P})}$ & $R_{Z(\mathrm{P})}$ & $R_{K_{\mathrm{DP}}(\mathrm{P})}$ & $R_{Z(\mathrm{P})}$ & $R_{K_{\mathrm{DP}}(\mathrm{P})}$ \\
\hline $\begin{array}{l}\text { Simulation period } \\
(2012 / 1-2012 / 12)\end{array}$ & $1,281.4$ & $1,272.6$ & $1,450.6$ & 0.968 & 0.976 & 2.926 & 2.848 & 0.936 & 0.953 & 0.69 & -13.20 \\
$\begin{array}{l}\text { Rainy period } \\
(2012 / 6,7,8,9)\end{array}$ & 940.8 & 906.9 & $1,001.2$ & 0.977 & 0.988 & 3.880 & 3.251 & 0.955 & 0.975 & 4.52 & -5.41 \\
$\begin{array}{l}\text { Dry period } \\
(2012 / 3,4,5,10,11)\end{array}$ & 263.6 & 293.0 & 361.3 & 0.877 & 0.902 & 2.620 & 2.904 & 0.769 & 0.813 & -11.14 & -37.07 \\
$\begin{array}{l}\text { Winter period } \\
(2012 / 1,2,12)\end{array}$ & 68.0 & 72.7 & 88.1 & 0.932 & 0.945 & 1.253 & 1.247 & 0.868 & 0.893 & -6.99 & -29.54 \\
\hline
\end{tabular}

TABLE 5: List of the ten days where $R_{Z(\mathrm{P})}$ and $R_{K_{\mathrm{DP}}(\mathrm{P})}$ results overestimated the rain gauge rainfall data the most.

\begin{tabular}{|c|c|c|c|c|c|c|c|}
\hline \multirow[b]{2}{*}{ Date } & \multicolumn{2}{|c|}{ Daily rainfall (mm) } & \multirow[b]{2}{*}{$\begin{array}{l}\text { Difference } \\
(\mathrm{mm})\end{array}$} & \multicolumn{4}{|c|}{ Daily rainfall (mm) } \\
\hline & $\begin{array}{l}\text { Rain gauge rainfall } \\
\text { data }\left(R_{\text {gauge }}\right)\end{array}$ & $\begin{array}{l}\text { Rain radar rainfall } \\
\text { data }\left(R_{Z(\mathrm{P})}\right)\end{array}$ & & Date & $\begin{array}{l}\text { Rain gauge rainfall } \\
\text { data }\left(R_{\text {gauge }}\right)\end{array}$ & $\begin{array}{l}\text { Rain radar rainfall } \\
\quad \text { data }\left(R_{K_{\mathrm{DP}}(\mathrm{P})}\right)\end{array}$ & $\begin{array}{c}\text { Difference } \\
(\mathrm{mm})\end{array}$ \\
\hline $2012-09-12$ & 0.0 & 29.2 & -29.2 & 2012-04-25 & 15.8 & 32.4 & -16.6 \\
\hline $2012-05-28$ & 5.2 & 19.1 & -13.9 & $2012-03-30$ & 11.4 & 27.9 & -16.5 \\
\hline 2012-05-08 & 5.4 & 18.8 & -13.4 & 2012-11-04 & 6.0 & 21.7 & -15.7 \\
\hline $2012-12-14$ & 15.4 & 28.3 & -12.9 & $2012-12-14$ & 15.4 & 29.8 & -14.4 \\
\hline 2012-11-04 & 6.0 & 18.3 & -12.3 & $2012-03-22$ & 5.2 & 18.3 & -13.1 \\
\hline $2012-08-16$ & 25.2 & 33.2 & -8.0 & $2012-07-06$ & 30.6 & 43.4 & -12.8 \\
\hline $2012-04-25$ & 15.8 & 22.8 & -7.0 & 2012-11-11 & 17.0 & 26.0 & -9.0 \\
\hline 2012-11-11 & 17.0 & 23.6 & -6.6 & $2012-08-20$ & 1.6 & 9.7 & -8.1 \\
\hline $2012-07-15$ & 19.2 & 25.7 & -6.5 & $2012-08-16$ & 25.2 & 33.1 & -7.9 \\
\hline $2012-03-22$ & 5.2 & 11.5 & -6.3 & $2012-07-15$ & 19.2 & 27.0 & -7.8 \\
\hline
\end{tabular}

TABLE 6: List of the ten days where $R_{Z(\mathrm{P})}$ and $R_{K_{\mathrm{DP}}(\mathrm{P})}$ results underestimated the rain gauge rainfall data the most.

\begin{tabular}{|c|c|c|c|c|c|c|c|}
\hline \multicolumn{3}{|c|}{ Daily rainfall (mm) } & \multirow[b]{2}{*}{$\begin{array}{l}\text { Difference } \\
(\mathrm{mm})\end{array}$} & \multicolumn{4}{|c|}{ Daily rainfall (mm) } \\
\hline Date & $\begin{array}{c}\text { Rain gauge rainfall } \\
\text { data }\left(R_{\text {gauge }}\right)\end{array}$ & $\begin{array}{l}\text { Rain radar rainfall } \\
\text { data }\left(R_{Z(\mathrm{P})}\right)\end{array}$ & & Date & $\begin{array}{c}\text { Rain gauge rainfall } \\
\text { data }\left(R_{\text {gauge }}\right)\end{array}$ & $\begin{array}{l}\text { Rain radar rainfall } \\
\quad \text { data }\left(R_{K_{\mathrm{DP}}(\mathrm{P})}\right)\end{array}$ & $\begin{array}{l}\text { Difference } \\
\quad(\mathrm{mm})\end{array}$ \\
\hline 2012-09-17 & 176.0 & 143.6 & 32.4 & 2012-08-30 & 69.0 & 51.9 & 17.1 \\
\hline $2012-08-28$ & 63.0 & 46.2 & 16.8 & $2012-03-23$ & 22.0 & 11.9 & 10.1 \\
\hline 2012-08-30 & 69.0 & 53.1 & 15.9 & $2012-08-28$ & 63.0 & 54.2 & 8.8 \\
\hline $2012-03-23$ & 22.0 & 11.1 & 10.9 & $2012-09-13$ & 9.6 & 2.6 & 7.0 \\
\hline $2012-05-14$ & 20.6 & 9.8 & 10.8 & 2012-09-17 & 176.0 & 170.4 & 5.6 \\
\hline 2012-09-13 & 9.6 & 1.1 & 8.5 & $2012-09-16$ & 69.0 & 64.2 & 4.8 \\
\hline 2012-09-16 & 69.0 & 61.1 & 7.9 & $2012-07-07$ & 5.2 & 0.7 & 4.5 \\
\hline $2012-04-21$ & 40.2 & 34.4 & 5.8 & $2012-06-12$ & 9.2 & 5.9 & 3.3 \\
\hline $2012-08-23$ & 34.2 & 28.6 & 5.6 & 2012-08-11 & 9.6 & 6.3 & 3.3 \\
\hline 2012-07-07 & 5.2 & 0.3 & 4.9 & 2012-03-04 & 6.2 & 3.0 & 3.2 \\
\hline
\end{tabular}

periods of calibration (2010), validation (2011), and simulation (2012). The parameters were corrected through runoff simulation for the period of correction using ground rainfall data. Using these parameters, the runoff analysis was carried out based on the SWAT model for the periods of calibration and simulation. The results from the runoff analysis were analyzed based on the general applicability evaluation criteria of the model presented by Moriasi et al. [25] in Section 3.3.
Figure 5 compares the observed and simulated streamflows for the periods of correction and calibration. The simulated streamflows obtained using the observed streamflow and $R_{\text {gauge }}$ during the period of correction are $20.7 \mathrm{~m}^{3} / \mathrm{sec}$ and $20.5 \mathrm{~m}^{3} / \mathrm{sec}$, respectively, and the means of the simulation streamflows using the observed streamflow and $R_{\text {gauge }}$ during the period of calibration are $22.7 \mathrm{~m}^{3} / \mathrm{sec}$ and $22.4 \mathrm{~m}^{3} / \mathrm{sec}$, respectively. As shown in Figure 5, the results of the runoff 


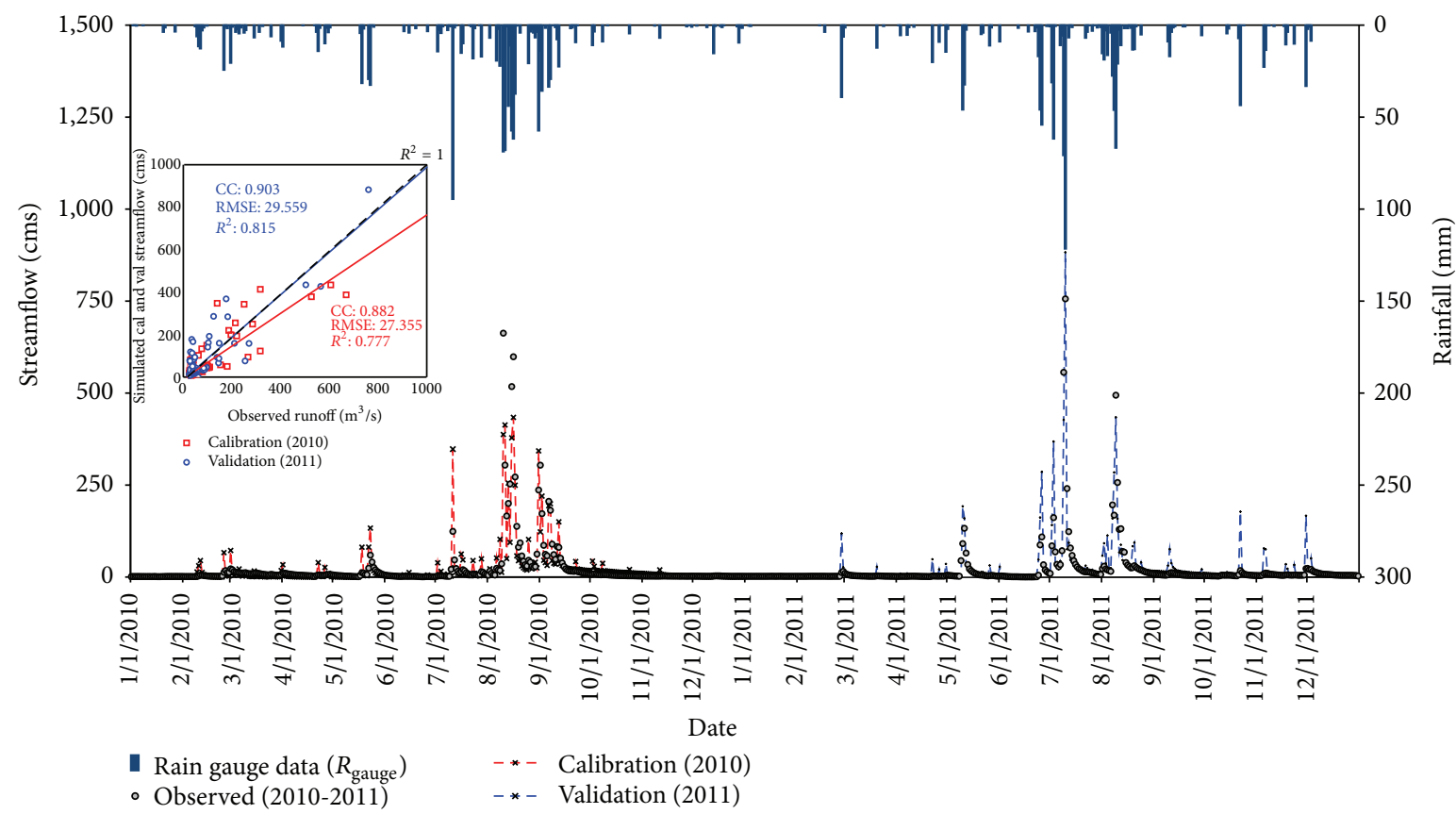

FIgURE 5: Calibration and validation of the SWAT model.

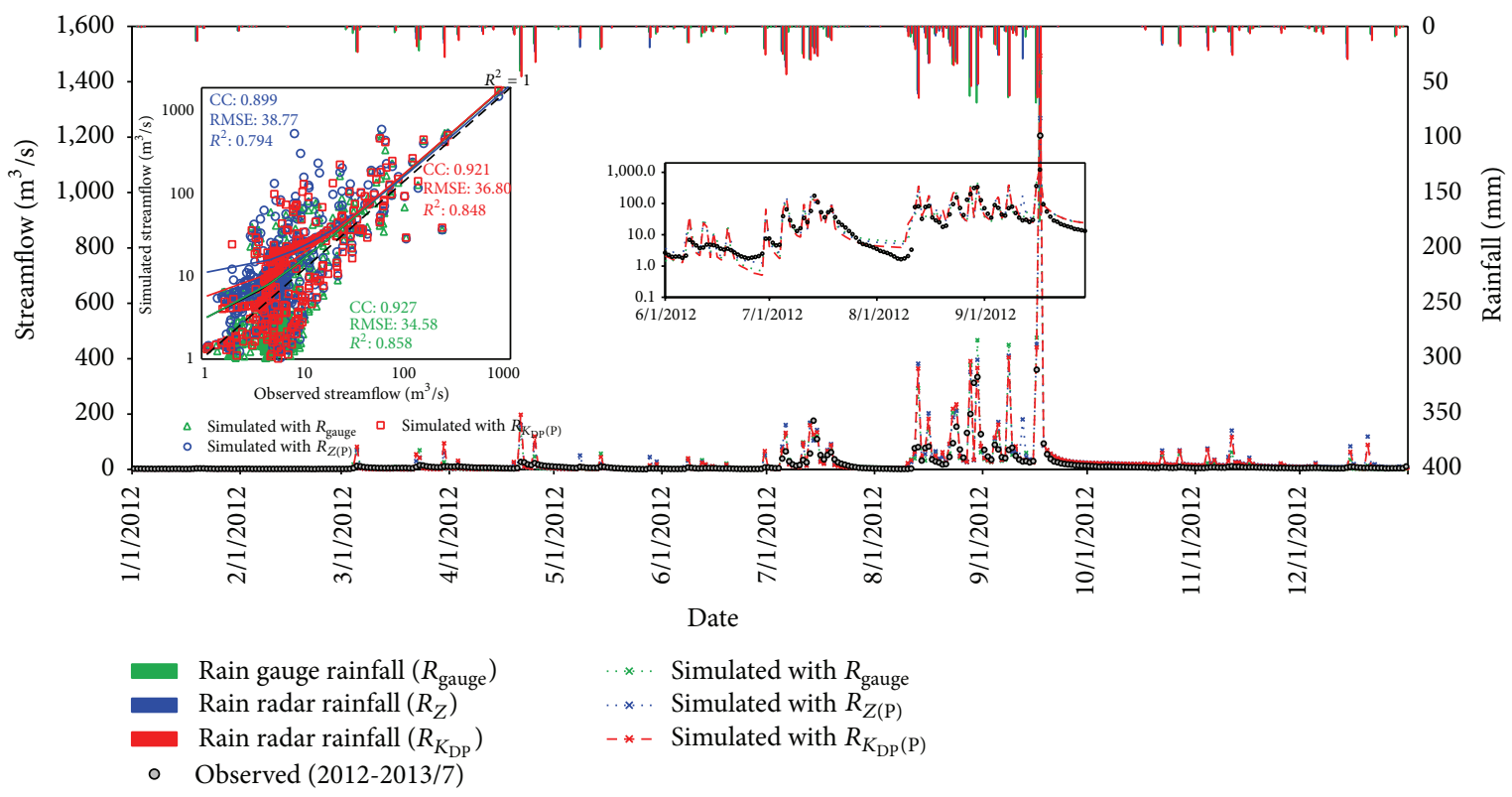

FIGURE 6: The results of the daily streamflow simulation (2012).

charge using $R_{\text {gauge }}$ for the periods of correction and calibration describe the entire characteristics of the daily unit runoff discharge relatively well. However, 2010/8/10 and 2010/8/15 16 during the period of calibration and 2011/8/9 during the period of validation are underestimated because the run-off discharge is relatively high. Moreover, as a result of evaluating the applicability of the SWAT model during the periods of correction and calibration, as presented in Table 7, the NSE values are 0.97 and 0.78 , respectively, the PBIAS (\%) values are 1.44 and -24.13 , respectively, and the RSR values are nearly 0.47 . The results from the runoff analysis during the periods of correction and calibration are a natural result of the application of the optimized model parameters of the correction period to the calibration period.

Figure 6 shows the results of daily streamflow hydrographs which applied $R_{Z(\mathrm{P})}$ and $R_{K_{\mathrm{DP}}(\mathrm{P})}$ to the model that completed its validation using the parameters calibrated earlier.

The mean of the observation streamflow during the period of simulation (2012) is $19.8 \mathrm{~m}^{3} / \mathrm{sec}$. The mean of the 
TABLE 7: Evaluation of the model applicability in the streamflow analysis.

\begin{tabular}{|c|c|c|c|c|}
\hline Classification & $\begin{array}{c}\text { Type of } \\
\text { rainfall data }\end{array}$ & NSE & RSR & PBIAS (\%) \\
\hline $\begin{array}{l}\text { Calibration } \\
(2010)\end{array}$ & $R_{\text {gauge }}$ & 0.97 (very good) & 0.47 (very good) & 1.46 (very good) \\
\hline $\begin{array}{l}\text { Validation } \\
(2011)\end{array}$ & $R_{\text {gauge }}$ & 0.78 (very good) & 0.47 (very good) & -24.13 (satisfactory) \\
\hline \multirow{3}{*}{$\begin{array}{l}\text { Simulation } \\
(2012)\end{array}$} & $R_{\text {gauge }}$ & 0.74 (good) & 0.51 (good) & -27.50 (unsatisfactory) \\
\hline & $R_{Z(\mathrm{P})}$ & 0.69 (good) & 0.55 (good) & -42.74 (unsatisfactory) \\
\hline & $R_{K_{\mathrm{DP}}(\mathrm{P})}$ & 0.72 (good) & 0.53 (good) & -44.79 (unsatisfactory) \\
\hline \multirow{3}{*}{$\begin{array}{l}\text { Simulation } \\
\text { (rainy or wet } \\
\text { season) }\end{array}$} & $R_{\text {gauge }}$ & 0.74 (good) & 0.51 (good) & -25.59 (unsatisfactory) \\
\hline & $R_{Z(\mathrm{P})}$ & 0.73 (good) & 0.52 (good) & -30.23 (unsatisfactory) \\
\hline & $R_{K_{\mathrm{DP}}(\mathrm{P})}$ & 0.75 (good) & 0.50 (very Good) & -29.80 (unsatisfactory) \\
\hline \multirow{3}{*}{$\begin{array}{l}\text { Simulation (dry } \\
\text { season) }\end{array}$} & $R_{\text {gauge }}$ & -8.91 (unsatisfactory) & 3.15 (very good) & -35.00 (unsatisfactory) \\
\hline & $R_{Z(\mathrm{P})}$ & -24.10 (unsatisfactory) & 5.01 (good) & -80.51 (unsatisfactory) \\
\hline & $R_{K_{\mathrm{DP}}(\mathrm{P})}$ & -23.40 (unsatisfactory) & 4.94 (very good) & -92.49 (unsatisfactory) \\
\hline
\end{tabular}

runoff discharge using the ground observation data is about $25.2 \mathrm{~m}^{3} / \mathrm{sec}$ and the mean values of the runoff discharge using $R_{Z(\mathrm{P})}$ and $R_{K_{\mathrm{DP}}(\mathrm{P})}$ are about $27.7 \mathrm{~m}^{3} / \mathrm{sec}$ and $28.1 \mathrm{~m}^{3} / \mathrm{sec}$, respectively. In other words, the average streamflows were higher when $R_{Z(\mathrm{P})}$ and $R_{K_{\mathrm{DP}}(\mathrm{P})}$ were used compared to when $R_{\text {gauge }}$ was used during the period of simulation (2012). The NSE, RSR, and PBIAS (\%) values, which are evaluation indexes for the applicability of the SWAT model during the period of simulation, showed more significant simulation results when $R_{\text {gauge }}$ was used compared to when $R_{Z(\mathrm{P})}$ and $R_{K_{\mathrm{DP}}(\mathrm{P})}$ were used (Table 7 ).

Similar to the rainfall comparison (Section 4.1), the runoff discharge analysis was carried out by classifying the season to either the rainy or wet season or the dry season depending on the characteristics of the rainfall and seasonal period. As a result, the NSE, RSR, and PBIAS (\%) values, which are evaluation indexes for the applicability of the SWAT model, during the rainy or wet season are $0.74,0.51$, and -25.59 , respectively, when $R_{\text {gauge }}$ was used and $0.73,0.52$, and -30.23 and $0.75,0.50$, and -29.80 when $R_{Z(\mathrm{P})}$ and $R_{K_{\mathrm{DP}}(\mathrm{P})}$ were used. In other words, it is significant to use $R_{Z(\mathrm{P})}$ and $R_{K_{\mathrm{DP}}(\mathrm{P})}$ in the rainy or wet season (Jun. to Sept.) when convection precipitation, which is at an intermediate level or higher (relatively high) in terms of rainfall intensity including heavy rains and typhoons, occurs frequently. Such a result is attributable to the fact that the QPE algorithms (Section 2.2) used in this study are optimized for rainfall observation in the form of convection precipitation with a high rainfall intensity for the purpose of forecasting and warning floods. If QPE algorithms are applied to observation strategies and algorithms for the purpose of stratiform rainfall or winter season observation, opposite results from those obtained in this study are expected.

Therefore, to increase the applicability of rain radarderived rainfall data in analyzing more than one year of long-term runoff (both daily and monthly time steps), it is necessary to take the development and application of algorithms into account to improve QPE algorithms as well as the accuracy of radar data.

\section{Conclusions}

In this study, we evaluated the applicability of long-term runoff simulation on a daily basis using rain radar-derived rainfall data with rain gauge data $\left(R_{\text {gauge }}\right)$.

The SWAT model, which is a semidistribution hydrologic model, was applied to the Gamcheon stream basin of the Nakdong River from 2010 to 2012. In addition, radar-derived point rainfall data $\left(R_{Z(\mathrm{P})}\right.$ and $\left.R_{K_{\mathrm{DP}}(\mathrm{P})}\right)$ and rain gauge data $\left(R_{\text {gauge }}\right)$ were compared prior to runoff simulation.

As a result of comparing the annual average accumulated amount of precipitation during the period of simulation (2012), $R_{Z(\mathrm{P})}$ and $R_{K_{\mathrm{DP}}(\mathrm{P})}$ underestimated $R_{\text {gauge }}$ by about $0.7 \%$ and overestimated $R_{\text {gauge }}$ by $13.2 \%$, respectively. The annual data were classified into the rainy or wet season and dry season depending on the characteristics of rainfall and seasonal period taking into account the typical rainfall distribution in Korea in Jun. to Sept. when heavy rain and typhoons occur in order to compare the average accumulated rainfall in the basin. As a result, $R_{Z(\mathrm{P})}$ and $R_{K_{\mathrm{DP}}(\mathrm{P})}$ had relatively lower errors compared to $R_{\text {gauge }}$ in the summer (rainy or wet season), but there were large errors because such values are overestimated in the dry season.

Based on the correlation coefficient $(R)$, runoff simulations using $R_{\text {gauge }}, R_{Z(\mathrm{P})}$, and $R_{K_{\mathrm{DP}}(\mathrm{P})}$ were carried out. As a result, the simulations described the characteristics of the changes of runoff on a daily basis well. The NSE, RSR, and PBIAS (\%) values, which are evaluation indexes for the applicability of the SWAT model, were evaluated in this study. As a result, the NSE and RSR values were appropriate, but PBIAS (\%) was negative in most cases. This suggests that the PBIAS (\%) is overestimated. In particular, as in the rainfall analysis, the runoff discharge analysis was classified into the rainy or wet season and dry season. As a result of the 
comparison of both seasons, the NSE, RSR, and PBIAS (\%) values in the rainy or wet season showed similar or more significant values when $R_{\text {gauge }}$ was used compared to when $R_{Z(\mathrm{P})}$ and $R_{K_{\mathrm{DP}}(\mathrm{P})}$ were used. But, in the dry season, the analysis did not match the ground observation rainfall data well $\left(R_{\text {gauge }}\right)$. Based on the results obtained to date, the QPE algorithms used in this study are highly applicable in runoff simulation from Jun. to Sept. (summer; rainy season) and less applicable in other periods (dry season; winter).

The results from this study suggest that it is necessary to select radar observation strategies and algorithms appropriately depending on the intended purpose of radar rainfall data. Therefore, further studies are needed to improve the bias correction and rainfall algorithms (in real time) to increase the usability of radar data in analyzing long-term runoff for more than one year (both daily and monthly time steps). Still, there is a limit to the accuracy of Quantitative Precipitation Estimation. But if the accuracy of Quantitative Precipitation Estimation can be improved sufficiently, the hydrological application scope of rain radar rainfall will be expanded sufficiently and more exact hydrologic analysis will become possible.

\section{Competing Interests}

The authors declare that they have no competing interests.

\section{Acknowledgments}

This research was supported by a grant from a Strategic Research Project (Development of Flood Warning and Snowfall Estimation Platform using Hydrological Radars) funded by the Korea Institute of Construction Technology.

\section{References}

[1] A. Berne and W. F. Krajewski, "Radar for hydrology: unfulfilled promise or unrecognized potential?" Advances in Water Resources, vol. 51, pp. 357-366, 2013.

[2] M. Borga, "Accuracy of radar rainfall estimates for streamflow simulation," Journal of Hydrology, vol. 267, no. 1-2, pp. 26-39, 2002.

[3] B. Anderl III, W. Attmannspacher, and G. A. Schultz, "Accuracy of reservoir inflow forecasts based on radar rainfall measurements," Water Resources Research, vol. 12, no. 2, pp. 217-223, 1976.

[4] I. D. Cluckie and M. D. Owens, "Real-time radar-runoff models and use of weather radar information," in Weather Radar and Flood Forecasting, V. Collinge and C. Kirby, Eds., pp. 171-190, John Wiley \& Sons, New York, NY, USA, 1987.

[5] N. Kouwen and G. Garland, "Resolution considerations in using radar rainfall data for flood forecasting," Canadian Journal of Civil Engineering, vol. 16, no. 3, pp. 279-289, 1989.

[6] J. Wyss, E. R. Williams, and R. L. Bras, "Hydrologic modeling of New England river basins using radar rainfall data," Journal of Geophysical Research, vol. 95, no. 3, pp. 2143-2152, 1990.

[7] G. S. Schell, C. A. Madramootoo, G. L. Austin, and R. S. Broughton, "Use of radar measured rainfall for hydrologic modelling," Canadian Agricultural Engineering, vol. 34, no. 1, pp. 41-48, 1992.
[8] W. P. James, C. G. Robinson, and J. F. Bell, "Radar-assisted realtime flood forecasting," Journal of Water Resources Planning and Management, vol. 119, no. 1, pp. 32-44, 1993.

[9] K. P. Georgakakos, J. A. Sperfslage, and A. K. Guetter, "Operational GIS based models for NEXRAD radar data in the US," in Proceedings of the International Conference on Water Resources and Environmental Research, vol. 1 of Water Resources and Environmental Research Center, pp. 603-609, Kyoto University, Kyoto, Japan, October 1996.

[10] V. A. Bell and R. J. Moore, "A grid-based distributed flood forecasting model for use with weather radar data: part 2. Case studies," Hydrology and Earth System Sciences, vol. 2, no. 2-3, pp. 283-298, 1998.

[11] B. E. Vieux and P. B. Bedient, "Estimation of rainfall for flood prediction from WSR-88D reflectivity: a case study, 17-18 October 1994," Weather and Forecasting, vol. 13, no. 2, pp. 407415, 1998.

[12] M. R. Knebl, Z.-L. Yang, K. Hutchison, and D. R. Maidment, "Regional scale flood modeling using NEXRAD rainfall, GIS, and HEC-HMS/RAS: a case study for the San Antonio River Basin Summer 2002 storm event," Journal of Environmental Management, vol. 75, no. 4, pp. 325-336, 2005.

[13] J. N. Diaz-Ramirez, W. H. McAnally, and J. L. Martin, "Sensitivity of simulating hydrologic processes to gauge and radar rainfall data in subtropical coastal catchments," Water Resources Management, vol. 26, no. 12, pp. 3515-3538, 2012.

[14] H. Noh, N. Kang, B. Kim, and H. Kim, "Flood simulation using vflo and radar rainfall adjustment data by statistical objective analysis," Journal of Korean Wetlands Society, vol. 14, no. 2, pp. 243-254, 2012.

[15] A. Fares, R. Awal, J. Michaud et al., "Rainfall-runoff modeling in a flashy tropical watershed using the distributed HL-RDHM model," Journal of Hydrology, vol. 519, pp. 3436-3447, 2014.

[16] F. Olivera, J. Choi, D. Kim, and M.-H. Li, "Estimation of average rainfall areal reduction factors in Texas using NEXRAD data," Journal of Hydrologic Engineering, vol. 13, no. 6, pp. 438-448, 2008.

[17] J. Choi, F. Olivera, and S. A. Socolofsky, "Storm identification and tracking algorithm for modeling of rainfall fields using 1-h NEXRAD rainfall data in Texas," Journal of Hydrologic Engineering, vol. 14, no. 7, pp. 721-730, 2009.

[18] M. Di Luzio and J. G. Arnold, "Formulation of a hybrid calibration approach for a physically based distributed model with NEXRAD data input," Journal of Hydrology, vol. 298, no. 1-4, pp. 136-154, 2004.

[19] R. Jayakrishnan, R. Srinivasan, C. Santhi, and J. G. Arnold, "Advances in the application of the SWAT model for water resources management," Hydrological Processes, vol. 19, no. 3, pp. 749-762, 2005.

[20] C. Jeong, K. Joo, W. Lee, H. Shin, and J.-H. Heo, "Estimation of optimal grid size for radar reflectivity using a SWAT model," Journal of Hydro-Environment Research, vol. 8, no. 1, pp. 20-31, 2014.

[21] A. M. Sexton, A. M. Sadeghi, X. Zhang, R. Srinivasan, and A. Shirmohammadi, "Using NEXRAD and rain gauge precipitation data for hydrologic calibration of SWAT in a northeastern watershed," Transactions of the ASABE, vol. 53, no. 5, pp. 15011510, 2010.

[22] K. Price, S. T. Purucker, S. R. Kraemer, J. E. Babendreier, and C. D. Knightes, "Comparison of radar and gauge precipitation data in watershed models across varying spatial and temporal scales," Hydrological Processes, vol. 28, no. 9, pp. 3505-3520, 2014. 
[23] R. S. Sekhon and R. C. Srivastava, "Doppler radar observations of drop-size distributions in a thunderstorm," Journal of the Atmospheric Sciences, vol. 28, no. 6, pp. 983-994, 1971.

[24] A. V. Ryzhkov, S. E. Giangrande, and T. J. Schuur, "Rainfall estimation with a polarimetric prototype of WSR-88D," Journal of Applied Meteorology, vol. 44, no. 4, pp. 502-515, 2005.

[25] D. N. Moriasi, J. G. Arnold, M. W. Van Liew, R. L. Bingner, R. D. Harmel, and T. L. Veith, "Model evaluation guidelines for systematic quantification of accuracy in watershed simulations," Transactions of the ASABE, vol. 50, no. 3, pp. 885-900, 2007.

[26] J. G. Arnold, Spatial scale variability in model developmentand parameterization [Ph.D. dissertation], Purdue University, West Lafayette, Ind, USA, 1992.

[27] J. G. Arnold, R. Srinivasan, R. S. Muttiah, and J. R. Williams, "Large area hydrologic modeling and assessment part I: model development," Journal of the American Water Resources Association, vol. 34, no. 1, pp. 73-89, 1998.

[28] S. Sorooshian and V. K. Gupta, "Model calibration," in Computer Models of Watershed Hydrology, V. P. Singh, Ed., pp. 23-68, Water Resources Publications, Fort Collins, Colo, USA, 1995.

[29] J. E. Nash and J. V. Sutcliffe, "River flow forecasting through conceptual models: part I-a discussion of principles," Journal of Hydrology, vol. 10, no. 3, pp. 282-290, 1970.

[30] H. V. Gupta, S. Sorooshian, and P. O. Yapo, "Status of automatic calibration for hydrologic models: comparison with multilevel expert calibration," Journal of Hydrologic Engineering, vol. 4, no. 2, pp. 135-143, 1999.

[31] T. S. Ramanarayanan, J. R. Williams, W. A. Dugas, L. M. Hauck, and A. M. S. McFarland, "Using APEX to identify alternative practices for animal waste management: part II. Model application," ASAE Paper 97-2209, ASAE, St. Joseph, Mich, USA, 1997.

[32] B. Engel, D. Storm, M. White, and J. G. Arnold, "A hydrologic/water quality model application protocol," Journal of the American Water Resources Association, vol. 43, no. 5, pp. 12231236, 2007.

[33] Korea Water Resources Association, Design Criteria Rivers Commentary, 2009. 

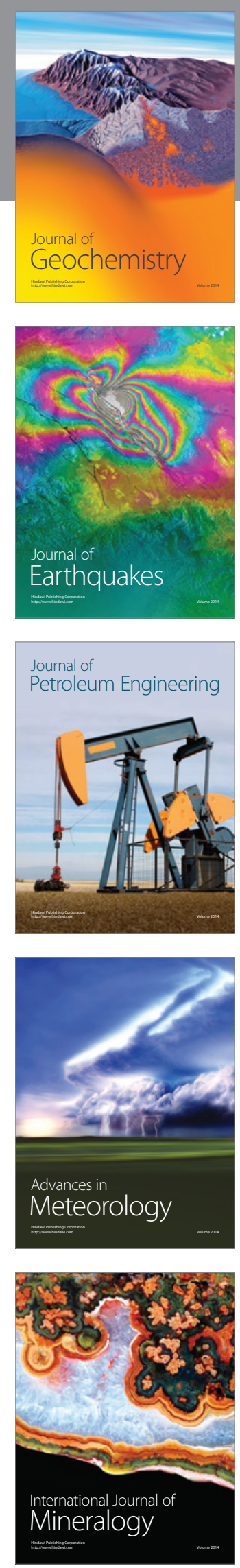
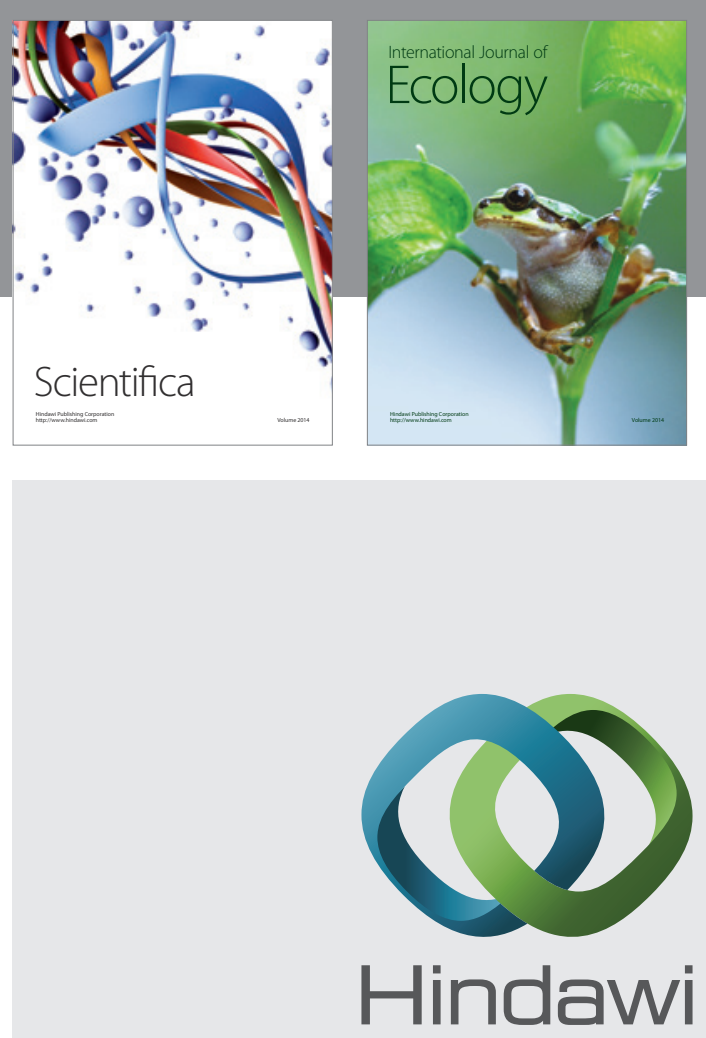

Submit your manuscripts at

http://www.hindawi.com
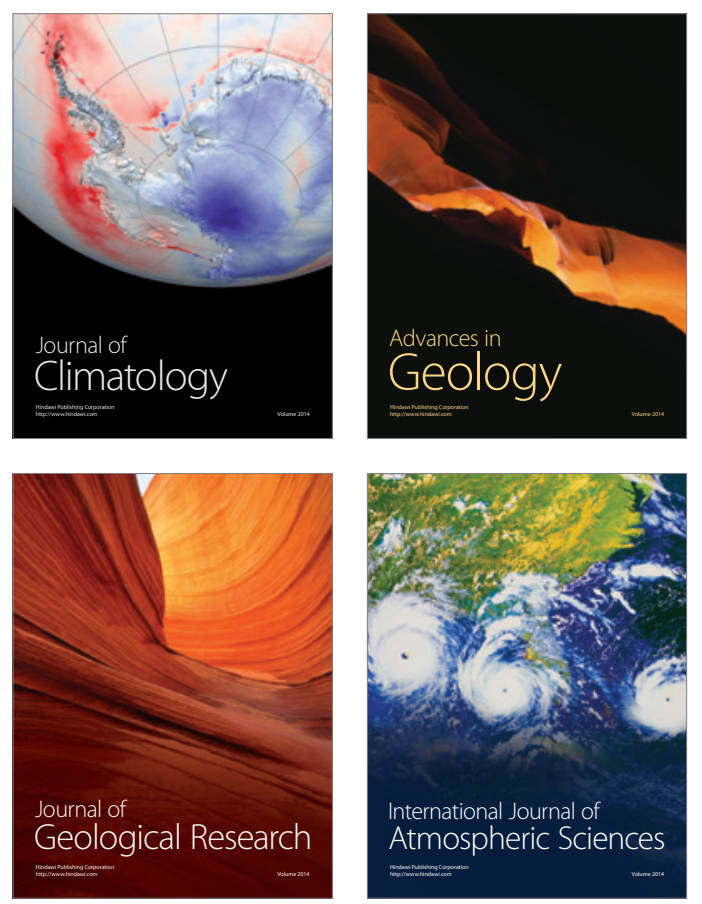

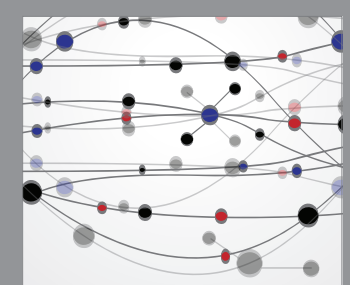

The Scientific

\section{World Journal}
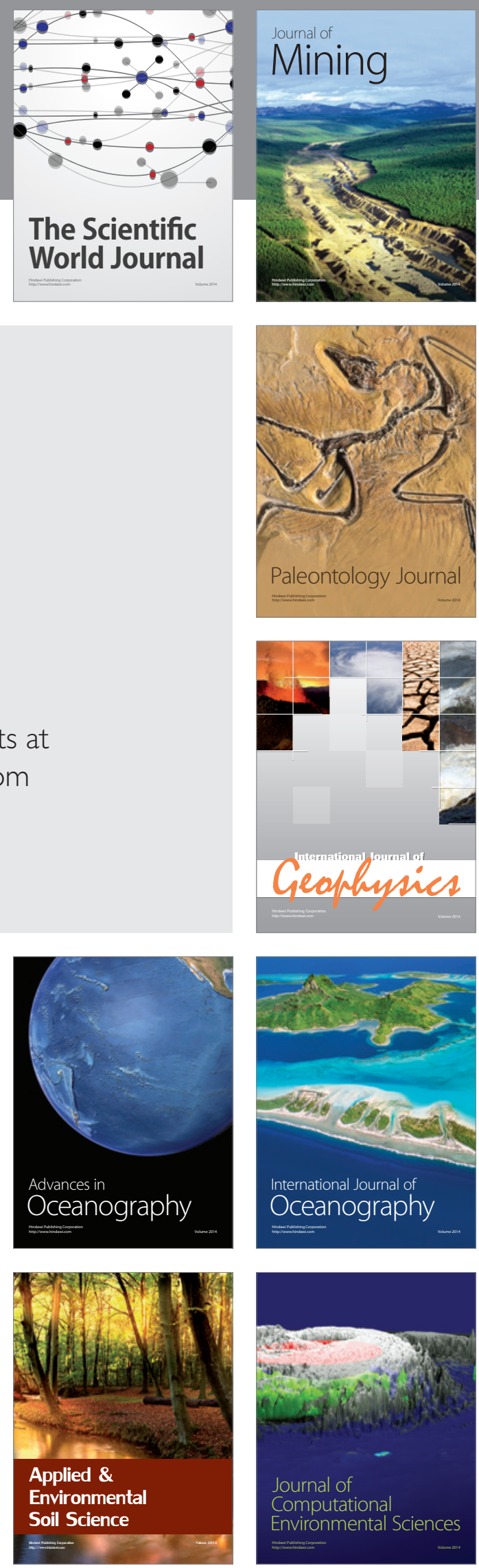